\title{
World Journal of Microbiology and Biotechnology: Serving the international microbiology community for 25 years
}

\author{
Colin Ratledge $\cdot$ Peter J. Large
}

Published online: 16 October 2009

(C) Springer Science+Business Media B.V. 2009

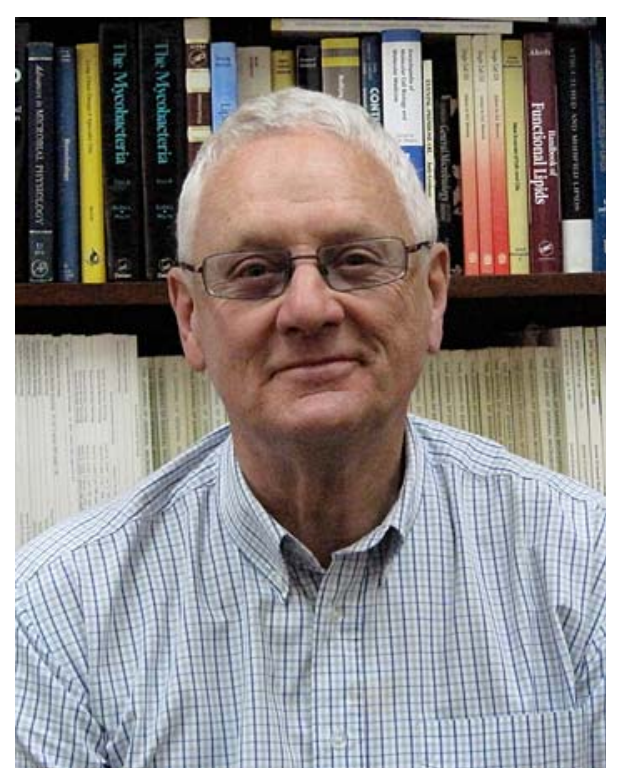

Fig. 1 Colin Ratledge

\section{History}

Edgar DaSilva, who died far too early in 2007 (Hoareau 2008), was the Head of the Microbiology Service for UNESCO, Paris. He had headed up a worldwide organization known as the MIRCEN network whose remit was to

C. Ratledge · P. J. Large $(\square)$

Department of Biological Sciences, University of Hull, HU6 7RX Hull, UK

e-mail: p.j.large@hull.ac.uk

C. Ratledge

e-mail: c.ratledge@hull.ac.uk develop applied microbiology and biotechnology throughout the developing world and, to this end, Edgar had created a number of laboratories in countries throughout the world but particularly in Asia, Africa and South America. In 1984 Edgar began serious discussions with Oxford University Press in the UK and, very happily, had the good fortune to come into contact with Anthony Watkinson who at that time was a senior editor with OUP. Edgar and Anthony felt that the time was now appropriate to launch a journal that would reflect the activities of UNESCO through its MIRCEN network of laboratories. Thus in 1985 was born the MIRCEN Journal of Applied Microbiology and Biotechnology. The Editors in Chief who were appointed to run the journal were Jacques Senez from Marseille in France and Fred Skinner in the UK. The Editors, in conjunction with Edgar, then compiled an Editorial Board that covered the entire range of microbiology and biotechnology and with the editorial board members being drawn from many different countries throughout the world. The remit of the journal was to provide an outlet for papers that described results of original work being carried out on topics that were relevant to the needs of the developing world. However, the journal was not restricted to recording experimental work just from the developing world nor from the MIRCEN laboratories. It was quite clear that in the 1980s there was a considerable number of scientists who were seriously concerned about the widening gap between the rich western countries and the poorer countries of the developing world, so much so that they themselves were developing ideas and initiatives that would help bridge this gap. There seemed, therefore, to be sufficient and exciting scientific work going on that would warrant the launch of this Journal. Oxford University Press, with its known reputation for being supportive of the developing world, was commendably instrumental in getting the Journal off to a flying start. 
After 5 years, it was clear that the MIRCEN Journal had outgrown its initial remit and was now beginning to make a small but significant contribution to microbiology and biotechnology across the entire world. It was therefore decided that the Journal should be re-launched in 1990 under its present title of the World Journal of Microbiology and Biotechnology. This was also stimulated by the desire of another publisher, Rapid Communications of Oxford Limited, to take over the journal from OUP. Indeed, OUP felt that it had done its share of philanthropy to launch the journal in the first place and, now that it was successfully holding its own on the international publishing stage, wished to pass the journal on to another publisher.

The decision to re-name the journal was taken after some discussion and debate between Anthony Watkinson, Edgar himself, Professor Stuart Glover of the University of Newcastle, UK and myself who had been invited to take over the role of Editor-in-Chief of the original MIRCEN Journal in 1987. The initial suggestion for the title of this Journal was, in fact, just to call it "World Microbiology". This, however, was thought to be insufficient and therefore World Journal of Microbiology was next suggested. Edgar then felt that the inclusion of 'biotechnology' in the title was essential and so, after very little further discussion, this was then agreed between us all and thus the present title came into being in 1990 . WJMB continued the remit of the original journal with the express intention of providing a means by which scientists from developing countries could publish the results of their research in a genuine international journal. The standard that had been set during the first 5 years was high and gratifyingly so. Indeed, it is worth remarking that during the first 5 years of its life, papers had been received and published from over 60 countries in the world making it all too evident that scientists worldwide had become increasingly concerned with the needs and requirements of the developing countries themselves. Very few if any other journals in the biosciences area could claim to have such a wide readership and such a wide geographic spread of contributing authors.

It is now a matter of fact that microbiology and biotechnology have helped in so many significant ways and in so many different countries to help improve the standard of overall science and also to help in the improvement of the general population. Resources, whether these are of materials or skilled manpower, are always in short supply in developing countries and their lack acts as one of the major impediments to poorer countries being able to catch up with the developed countries. It is all too clear that every possible stimulation has to given to the improvement in the wellbeing and education of all peoples throughout the world but to none more so that the peoples of the poorest countries. The imbalance that we now see between the rich and poor countries is an affront to everyone living in a developed country. Of course, microbiology and biotechnology can accomplish only so much in poor countries. Nevertheless, these subjects are key ones for the provision of adequate supplies of energy and clean water, for better health-care, including the treatment and diagnosis of disease, for improvements in agriculture and food production and in the prevention of waste and for the recycling of materials.

During the early years of WJMB, generous support was received from the International Union of Microbiological Sciences (IUMS) and, indeed, IUMS supported the journal until 1998. This period of close cooperation between IUMS and UNESCO was unique and provided a considerable driving force to help improve communications between microbiologists and biotechnologists on a worldwide basis. It was therefore with considerable regret that the World Journal lost its support from IUMS for reasons that were never made clear to either the publishers or editors of the World Journal.

\section{The present and the future}

The World Journal, very pleasingly, however, has not suffered by this withdrawal of support from IUMS but has, in fact, continued to go from strength to strength. It now publishes a massive number of papers each year that continue to be drawn from the widest number of countries, and its impact factor has risen from 0.538 in 2000 to 0.945 in 2008 . It has been a pleasure for one of us (CR) to have been associated with the journal since its very beginning, when he was a member of the very first editorial board, and then serving as Editor-in-Chief until 2005. It has given great satisfaction to see how the journal has become very much the key one for reporting on research work in microbiology and biotechnology that affect so many people in so many different countries. It is, indeed, a tribute to the journal and its present editors that it continues to fulfil this function so well as and so ably. The journal is often criticized for having a rather low impact factor but this completely misses the point of the impact that the journal and its contents have on the continuing network of MIRCEN laboratories throughout the world. The journal is concerned with communication: in helping developing countries to communicate with each other and to enable scientists to present the results of their work that very often use the simplest methods and technologies but often produce some very surprising and useful results.

One may often ask of a journal that if it did not exist would a similar one have to be created or would its absence from the bookshelves of the world not be missed? For the World Journal, the answer is an emphatic No: the journal has a unique niche in the plethora of scientific journals and especially in those in the microbiology and biotechnology arena. If the World Journal did not exist, there would be a 
severe gap that would not be taken up and filled by any other journal. The World Journal can therefore proudly proclaim that it has served the developing countries in a unique manner, and without it these key subjects would have been at a severe disadvantage. Not many other journals could make such claims.

It is, though important to appreciate that the World Journal speaks for all microbiologists and all biotechnologists and not just for those in the developing countries. In truth, the developing countries have had a raw deal over many decades, if not centuries, from people in the developed world. It is incumbent, therefore, on those scientists who enjoy a high standard of living and also generous support for their research that they should give some thought and consideration to their fellow scientists whose budgets are often only a few percent of those enjoyed by themselves. Help and support is always needed and this can be by scientists not only making their presence felt but also by them using their skills and expertise to develop their research that meets the needs of people in the poorer countries. It is gratifying therefore that so much current research can be seen to be applied for the benefit of people in the poorer countries; one may look at the developments in soil microbiology, resource utilization and exploitation, the development of antimicrobial agents and anti-parasitic agents for the treatment of tropical diseases and also for the provision of improved and safer foods, clean water and better sanitation. These are not trivial pursuits but they need the collaboration and cooperation between all scientists. The problems of the developing world need to be identified by the scientists who live in those countries and then communicated clearly to scientists in the more prosperous countries so that collaborative research work can be carried out between the different laboratories for the benefit of all. Too few scientists in western countries take the trouble to spend any appreciable time living and working with scientists and people in the developing countries. Where this does happen, the results can be truly amazing. To give just one example, the understanding and treatment of tropical diseases and also some diseases that continue to afflict developing countries, such as tuberculosis and malaria, are best appreciated by seeing what happens to people suffering from these diseases in the poorest countries of the world. We, in the western countries, cannot idly stand by and ignore three-quarters of the world's population that continue to suffer the most appalling social conditions and endure some of the terrible diseases. The World Journal of Microbiology and Biotechnology is a small but important cog in trying to rectify this huge imbalance in resources.

Now that I have retired from being Editor-in-Chief of the journal, I leave it confidently that it is in safe hands and will continue to serve a worldwide community and especially biological scientists throughout the world. The World Journal is truly unique and long may it continue to thrive and be an invaluable and unique means of publishing in a highly competitive scientific world.

\section{Reference}

Hoareau L (2008) Edgar DaSilva (1941-2007). World J Microbiol Biotechnol 24:595-597 